\title{
Reseña
}

\section{¿Para qué un medio escolar?}

https: / / doi.org/10.18566/comunica.n45.a05

Recibido: 5 de abril de 2021

Aceptado: 31 de mayo de 2021

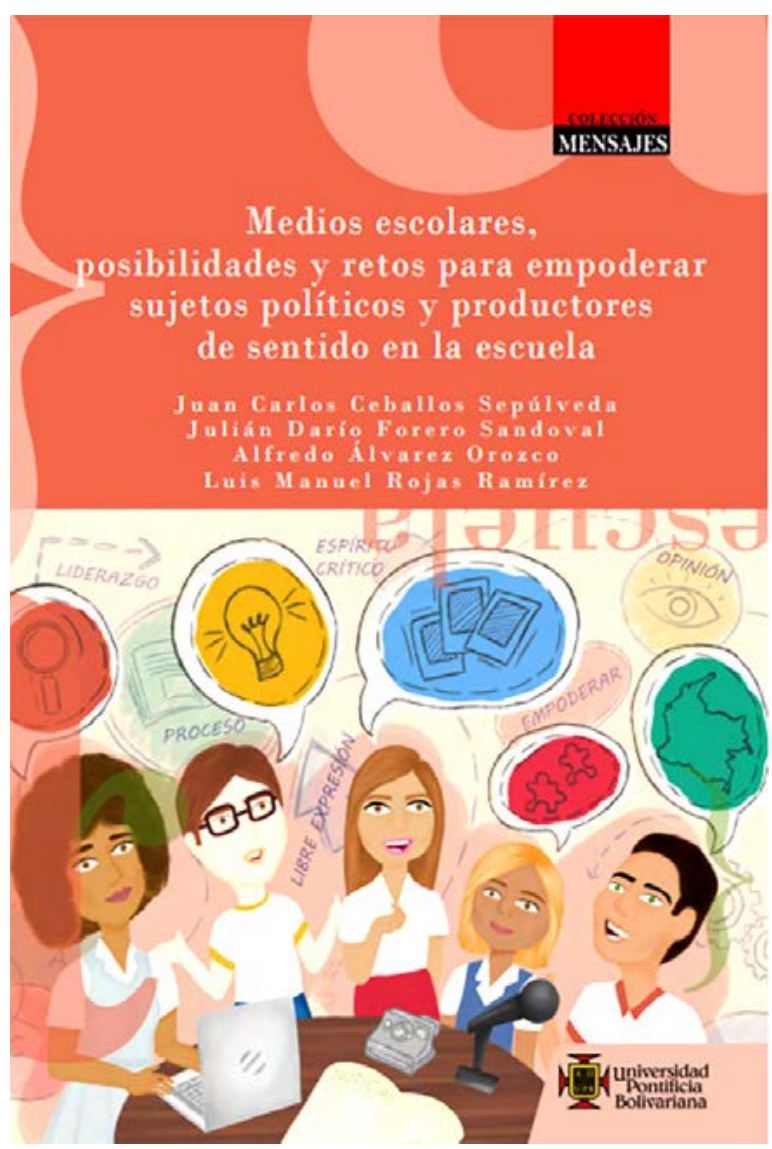

Disponible para su descarga gratuita en http:// hdl.handle. net/20.500.11912/5210
Quiero comenzar la reseña de esta publicación con una pregunta que he hecho durante mi vida profesional a jóvenes, maestros y bibliotecarios de una veintena de instituciones educativas de Antioquia, oficiales y no oficiales, desde mi rol como coordinadora del Programa Prensa Escuela de El Colombiano: ¿para qué quieren un medio escolar? Nunca la he formulado como pregunta de investigación porque no tengo experiencia como investigadora, y por eso mucho de lo que voy a comentar aquí será desde las experiencias que he vivido en Prensa Escuela en dos componentes, ambos con un eje fundamental y transversal: la formación ciudadana.

El primer componente es la formación de maestros y mediadores de los procesos de lectura y escritura para que usen la información de actualidad como un elemento valioso a la hora de construir conocimiento. comunicación

número 45

Julio - diciembre

$2021 \mid$ pp. $73-78$

Clara

Tamayo Palacio

Comunicadora Social -

Periodista. Coordinadora del Programa Prensa Escuela, El Colombiano.

clarat@elcolombiano.com.

co 
El segundo componente, el más relevante para lo que concierne a esta reseña, es la formación de jóvenes de $8 .^{\circ}$ grado a $11 .^{\circ}$ grado en el Taller Prensa Escuela, una metodología que promueve la narración de historias de la realidad de los jóvenes a partir de elementos básicos de los géneros periodísticos, como la crónica, el perfil y la entrevista. Este trabajo lo desarrollamos en alianza con las facultades de Comunicación Social Periodismo y de Educación de las universidades Pontificia Bolivariana y San Buenaventura.

La lectura de Medios escolares, posibilidades y retos para empoderar sujetos políticos y productores de sentido en la escuela, ${ }^{2}$ de Juan Carlos Ceballos Sepúlveda, Julián Darío Forero Sandoval, Alfredo Álvarez Orozco y Luis Manuel Rojas Ramírez, me ha permitido encontrar respuestas para esta pregunta.

A lo largo de mi trabajo con Prensa Escuela no he conocido un medio escolar que se identifique de forma integral con lo que propiciamos: medios escolares planteados desde una dimensión comunicativa de la ciudadanía, como lo propone Carlos Eduardo Valderrama en su libro Educomunicación: más allá del 2.0 (Valderrama, 2010), donde el diálogo, la narración, la interpretación, el sentido político de la comunicación y la manera como las tecnologías de la información han creado diversos métodos de interacción permitan que los medios escolares trasciendan la información institucional y replanteen las relaciones jerárquicas que desconfían de los jóvenes y de su capacidad de discernimiento.

El objetivo de esta investigación era "estudiar y analizar críticamente los medios escolares como espacios de formación del sujeto político"; y, en esa medida, me parece que fue muy conveniente abordar la temática comprendiendo desde adentro los medios escolares, para lo cual lo más indicado era elegir aquellos en los que pudieran adentrarse y desarrollar un estudio cualitativo de corte etnográfico, como lo describen los investigadores.

El análisis de experiencias en instituciones oficiales y no oficiales también aporta muchas luces acerca de la aproximación a un medio escolar desde las distintas perspectivas del manejo de la autoridad y las formas de acompañamiento de parte de las directivas. Muchas pistas nos quedan sobre cómo se genera autonomía en los estudiantes a partir de cómo se les demuestra confianza, se les delegan responsabilidades y se les deja explorar un camino en el que, de verdad, puedan ser los productores de sentido y personas capaces de asumirse como sujetos políticos.
1 Pueden ampliar la información aquí: https:// www.elcolombiano.com/blogs/ prensaescuela/category/2020

2 Disponible para su descarga gratuita en http://hdl.handle. net $/ 20.500 .11912 / 5210$ 


\section{La teoría nos devuelve a lo fundamental}

El primer capítulo del libro, "Apuesta teórica", recoge los principios que deben sustentar el desarrollo de los medios escolares a la luz de académicos que no solamente han escrito desde el deber ser, sino que han trabajado con jóvenes en la escuela, como el mismo Célestin Freinet a comienzos del siglo XX. Lo fundamental está en escuchar, en dar elementos para narrar la realidad. Freinet nos muestra que el camino es permitir a niños y jóvenes escribir para ser leídos. Y ese era el momento de la imprenta; el momento de hoy es el de una multiplicidad de tecnologías que nos llevan a audiencias, en muchos casos, comparables con las de los medios masivos; pero lo esencial sigue siendo lo mismo: cómo me atrevo a tomar la palabra, cómo me hago responsable de ella, cómo me expreso no pensando solamente en mi interés propio, sino a favor del bien común.

En este capítulo se dan cita referentes con los que también hemos trabajado en Prensa Escuela: Célestin Freinet, Paulo Freire, Adela Cortina, Carlos Eduardo Valderrama, Jesús Martín Barbero y Mario Kaplún, entre otros, y a la luz de todas sus posturas teóricas surge la que, para mí, es la gran pregunta, de este capítulo y de todo el libro: ¿están desarrollándose los medios escolares como transmisores de información o están generando realmente procesos de construcción de sentidos?

Con base en esta pregunta y en las experiencias que conozco en distintas instituciones educativas, me formulo otra: ¿cómo podemos plantear el desarrollo de un medio escolar como eje fundamental del proceso pedagógico para la formación ciudadana? Leer este texto es una buena manera de empezar.

En este libro hay múltiples posibilidades de articulación que ofrecen los medios escolares para promover transformaciones sociales importantes a partir de la narración de realidades, sustentada en la empatía y el reconocimiento del otro. Un medio de comunicación en el ámbito escolar implica, indefectiblemente, dialogar, y ese es justamente el ejercicio más trascendental para construir la ciudadanía.

Un medio escolar es, a mi juicio, un laboratorio social que, bien orientado, puede procurar los mejores resultados. ¿En qué se traducirán? Como lo dice este texto, en personas capaces de escuchar, de resolver las diferencias sin agredir la dignidad de los demás, en el reconocimiento de lo público, en la construcción de una memoria colectiva, entre muchas otras opciones que dependerán de la filosofía y de los propósitos con los que directivos y docentes asuman esta misión. 


\section{Entrar a la escuela, observar e interpretar}

Este capítulo define una metodología de investigación muy bien planteada, por cuanto se detiene en el proceso, lo valora y hace hallazgos más allá del producto. Es decir, no bastó con desmenuzar lo que los jóvenes publican, sino que hay un trabajo juicioso para entender cómo llegan a sus productos finales, bien sean periódicos murales, programas de radio o videos; mucho más allá, da cuenta de qué pasó para llegar a ellos, nos muestra los debates, las dificultades y los dilemas que enfrentan los jóvenes y los maestros cuando asumen la responsabilidad de producir el medio escolar.

En esta investigación hay un equilibrio muy interesante entre el rigor académico y la disposición para observar, para escuchar e interpretar, sabiendo tomar distancia, con mucho respeto, para no vulnerar ni influir en los procesos en los cuales los jóvenes avanzan.

\section{Medios escolares: diversidad de plataformas, mensajes y metodologías}

En los capítulos 3, 4, 5 y 6 los autores describen y contrastan experiencias de medios escolares en diferentes ciudades: Medellín, Envigado y Caldas en Antioquia; Montería en Córdoba y Bucaramanga en Santander.

La descripción de las experiencias por capítulos es muy útil. En cada medio, el análisis según las estructuras de lo público y lo privado es muy interesante, pues determina, en gran parte, cómo los jóvenes se relacionan con la autoridad, desarrollan su autonomía y ejercen el poder de acuerdo con el rol que representan.

\section{Los medios escolares como formadores de sujetos políticos son posibles}

El fin de esta publicación es el comienzo de muchas oportunidades para desarrollar un sentido de la democracia desde la vida escolar a través de unos medios de comunicación que se asuman como ejes transversales del proceso pedagógico; medios que llamen a niños y jóvenes a centrarse en la relevancia de la información, de la narración de las realidades desde distintas perspectivas, entendiendo, como dice la escritora nigeriana Chimamanda Ngozi Adichie, que no hay una sola historia.

Los medios escolares son un camino para el encuentro y el disentimiento; un camino para el desarrollo de la autonomía, que implica la capacidad 
de hacerse cargo de las opiniones y de las acciones; son un camino para apropiarse de formatos para expresar las historias propias y construir memoria colectiva. Los medios escolares son un camino con tantos senderos como quieran los maestros, directivos docentes, bibliotecarios y mediadores en sus procesos de formación. Los medios escolares pueden tener innumerables destinos y metas, según el recorrido lo permita: todo dependerá de cómo se transite, del equipaje que se lleve y de la actitud y los propósitos de quienes se asuman como guías de ese viaje.

Durante toda la lectura del libro me acompañó la filósofa Martha Nussbaum y quiero cerrar esta reseña con un fragmento de Sin fines de lucro. Por qué la democracia necesita de las humanidades (Nussbaum, 2010); lo traigo a colación para decir que los medios de información escolar son una de las semillas más prometedoras de la democracia en una institución que, paradójicamente, en muchos casos no la honra y no la comprende en su dimensión pedagógica. Nussbaum le hace una gran pregunta a la escuela en el capítulo "Educar ciudadanos": “¿Qué es lo que puede y debe hacer la escuela para generar ciudadanos de la democracia?" (Nussbaum, 2010, p. 73). Esta es una síntesis de lo que ella propone: la escuela puede desarrollar la capacidad del alumno de ver el mundo desde la perspectiva del otro, así como la de sentir un interés genuino por los demás, ya sea que estén cerca o lejos. En el ámbito escolar es donde, especialmente, se propicia el sentido de la responsabilidad individual tratando a cada niño como un agente responsable de sus actos. Y, para mí, este sería uno de los aportes fundamentales de la escuela desde la perspectiva de los medios escolares: “... promover activamente el pensamiento crítico, así como la habilidad y el coraje de expresarlo, aunque disienta de los demás" (Nussbaum, 2010, p. 74).

Es verdad, como dice Nussbaum (2010): “... se trata de un plan muy ambicioso que debe ponerse en marcha con un gran conocimiento de los problemas sociales y los recursos de cada lugar, sin perder de vista en ningún momento las circunstancias sociales" (Nussbaum, 2010, p. 74); es decir, sin perder de vista el contexto, los sentimientos, intereses y necesidades de los estudiantes. Considero que todo esto encaja perfectamente con lo que un medio escolar puede potenciar en la vida misma de la escuela, en la construcción de conocimiento y de una sociedad equitativa.

Medios escolares, posibilidades y retos para empoderar sujetos políticos y productores de sentido en la escuela es una lectura relevante, constructiva y aportante para todo aquel que dedique su vida a la educación, a la formación ciudadana, al fomento de la lectura con criterio y de la expresión de opiniones con responsabilidad, en el marco de un sentido colectivo y humanizador. 


\section{Referencias}

Nussbaum, M. C. (2010). Sin fines de lucro. Por qué la democracia necesita de las humanidades. Princeton University Press.

Trademark, T. [Productor]. (2009). Ted Talk: el peligro de la historia única [Película]. YouTube. https: / / www.youtube.com/watch?v=D9lhs241zeg

Valderrama, C. (2010). Educomunicación: más allá del 2.0. Editorial Gedisa. 